\title{
Comparative Anatomy of the Forearm and Hand of Wildcat (Leopardus geoffroyi), Ocelot (Leopardus pardalis) and Jaguar (Panthera onca)
}

\author{
H. L. Sánchez ${ }^{1}$ \\ E. L. Portiansky² \\ ${ }^{1}$ Institute of Anatomy, Facultad de Ciencias Veterinarias, Universidad \\ Nacional de la Plata, La Plata, Argentina \\ 2 Image Analysis Laboratory, Facultad de Ciencias Veterinarias, \\ Universidad Nacional de la Plata, La Plata, Argentina
}

Address for correspondence Mg. HL. Sánchez, Instituto de Anatomia, Facultad de Ciencias Veterinarias, Universidad Nacional de la Plata, Calle 60 y 118, s/n , CP 1900, CC296, La Plata, Argentina (e-mail: lilianasanchez@fcv.unlp.edu.ar).

J Morphol Sci 2019;36:7-13.

\section{Introduction}

Argentina is the only country in the American continent that has all the species of felines present in South America. With the exception of the red lynx (Lynx rufus) and of the Canada lynx (Lynx canadensis), which only inhabit North America, the remaining 10 species that inhabit the continent have part of their distribution in Argentina. However, very little is known about most of these autochthonous species. From the jaguar (Panthera onca) to the wildcat (Leopardus geoffroyi), the largest and the smallest of the American felines, respectively, all of the South American wild cats are almost unknown to science. ${ }^{1}$ Currently, most of these native felines are protected in Argentina. However, the deep ignorance that exists about their anatomy could hinder actions tending to received

August 30, 2018

accepted

January 6, 2019

published online

March 7, 2019
DOI https://doi.org/

10.1055/s-0039-1681016. ISSN 2177-0298.
Copyright (c) 2019 by Thieme Revinter

Publicações Ltda, Rio de Janeiro, Brazil
License terms

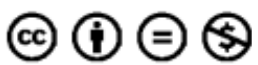


their effective preservation and management in the areas destined to their preservation. ${ }^{2}$

For a long time, the domestic cat has been the biological model used for the study of different feline species, mainly due to the greater availability of specimens. The lower availability of material from the other species significantly limits their study. ${ }^{3}$ From the agreement of collaboration maintained by the Facultad de Ciencias Veterinarias of the Universidad Nacional de la Plata with the zoo of the municipality of La Plata, which cedes the dead specimens to our Instituto de Anatomia, we began to study the locomotor apparatus and the peripheral nervous system of the jaguar and of the puma. ${ }^{4,5}$

Although some aspects related to ecology, reproduction and nutrition are known, there is not much information related to the anatomy of these autochthonous species, especially to their locomotor system. The description of the muscles of these feline species is particularly useful for phylogenetic studies. ${ }^{6}$ Comparative studies of these taxa and homologies show the evolution of their muscles, as well as a very careful review and clarification of the nomenclature used based on the Nomina Anatomica Veterinaria. 7,8

Knowledge about the anatomical region of the forearm and of the hand is of high importance to understand the hunting and movement habits of these animals. ${ }^{9}$ Thus, some species of felines, such as the serval (Leptailurus serval), have developed long and thin thoracic limbs, to which is added the great development of auricular pavilions, which they use to detect the prey in tall grass. ${ }^{5,10}$ In contrast, other species of felines, such as the jaguar, have developed shorter thoracic limbs, with well-developed arms and forearms that allow them to grab the prey strongly. ${ }^{11}$

The lack of knowledge about the muscles of the forearm and of the hand of these felines poses difficulties for the discussion not only of their morphology, but also of their function and of the evolution of these native felines. The objective of the present study was to carry out a descriptive analysis of the forearm and hand muscles of wildcats, ocelots and jaguars and to compare them with the data recorded for the domestic cat. Likewise, the accuracy of the homologies, as well as of the nomenclature used among these feline species for the description of the muscles, was critically examined and discussed.

\section{Materials and Methods}

Muscles of the right and left thoracic limbs of 1 adult male jaguar (body weight [BW]: $78 \mathrm{~kg}$ ) and of 1 young female ocelot (BW: $7 \mathrm{~kg}$ ) that died of natural causes in the zoo of the municipality of La Plata were dissected. A total of 3 wildcats, 1 young female (BW: $3 \mathrm{~kg}$ ) and 2 adult males (BWs between 3.6 and $4 \mathrm{Kg}$ ), found dead in the field or on the route of Mount Berisso, in the province of Buenos Aires, were also used.

The animals were frozen and stored in the Instituto de Anatomia of the Facultad de Ciencias Veterinarias of the Universidad Nacional de la Plata. They were then fixed with a fixing solution composed of $10 \%$ formaldehyde, $1 \mathrm{~L}$ of carbolic acid, $1 \mathrm{~L}$ of glycerin, and $5 \mathrm{~g}$ of thymol. The common carotid arteries were channeled, and an amount of fixative liquid equivalent to $10 \%$ of the BW of each animal was injected. At each stage of the dissection, the muscles were photographed with a Sony Cyber-Shot DSC-P10 digital camera (Sony Corporation, Tokyo, Japan). The Adobe Photoshop CS6 software (Adobe Inc., San Jose, CA, USA) was used to process the images.

The following variables were analyzed: presence of muscles, length of the muscles, length of the muscular bellies, length of the tendons from their origin to their insertion, and some morphological variations of the muscles were compared between the three studied feline species. The measurements were made using a $300 \mathrm{~mm}$ Vernier caliper (200 mm, Isard, China).

\section{Results}

The extensor carpi radialis muscle of the ocelot and of the jaguar showed a great development of the long and short heads, compared with that of the wildcat. Both muscular bellies originated in the lateral supracondylar ridge, distal to the humerus bone. The long head was inserted into the dorsal surface of the second metacarpal, and the short head at the base of the third metacarpal (-Fig. 1A, 2A). The extensor digitorum communis muscle of the three species was formed by two bellies: medial and lateral. However, the lateral digital extensor muscle of the jaguar had only one belly, whereas in the wildcat and in the ocelot, it was clearly divided into two bellies, of which the medial belly was divided again into two tendons ( $\mathbf{F i g}$. 3A, C). The abductor digiti longus muscle of the first finger showed a more proximal origin in the jaguar and in the ocelot than in the wildcat. It originated along the entire length of the lateral edge of the ulna, in the proximal two thirds of the radius and in the interosseous membrane of the forearm. In the jaguar and in the ocelot, the extensor digiti I and the extensor digiti II muscles originated in the proximal third of the diaphysis of the ulna and were divided into two bellies. The belly of finger I was continued with two tendons, which then fused, forming an expansion in its insertion in the distal phalanx. The belly of finger II had a single tendon, which fused with the tendon of the extensor digitorum lateralis muscle of finger II (-Fig. 2B).

The flexor muscles showed no relevant differences between the felines studied. The palmaris longus muscle of the ocelot and of the jaguar, located medial to the forearm, ended in five tendons, while in the wildcat it was divided into four tendons (-Fig. 1B, 3B). In the three wild species, they ended up attached to the tendons of the flexor digitorum superficialis muscle in the proximal extremity of the middle phalanx.

In the three South American felines, the flexor digitorum superficialis muscle was formed by two heads: one ulnar and one radial, which united to form a common belly. Particularly in the jaguar, this muscle formed a thick and flattened muscular belly that later became divided into four tendons, one for each finger (-Fig. 1B).

In felines, the flexor digitorum profundus muscle has five heads (-Fig. 1B, 3B); the first head, or superficial head, is the ulnar. The second, third and fourth heads originate from the 

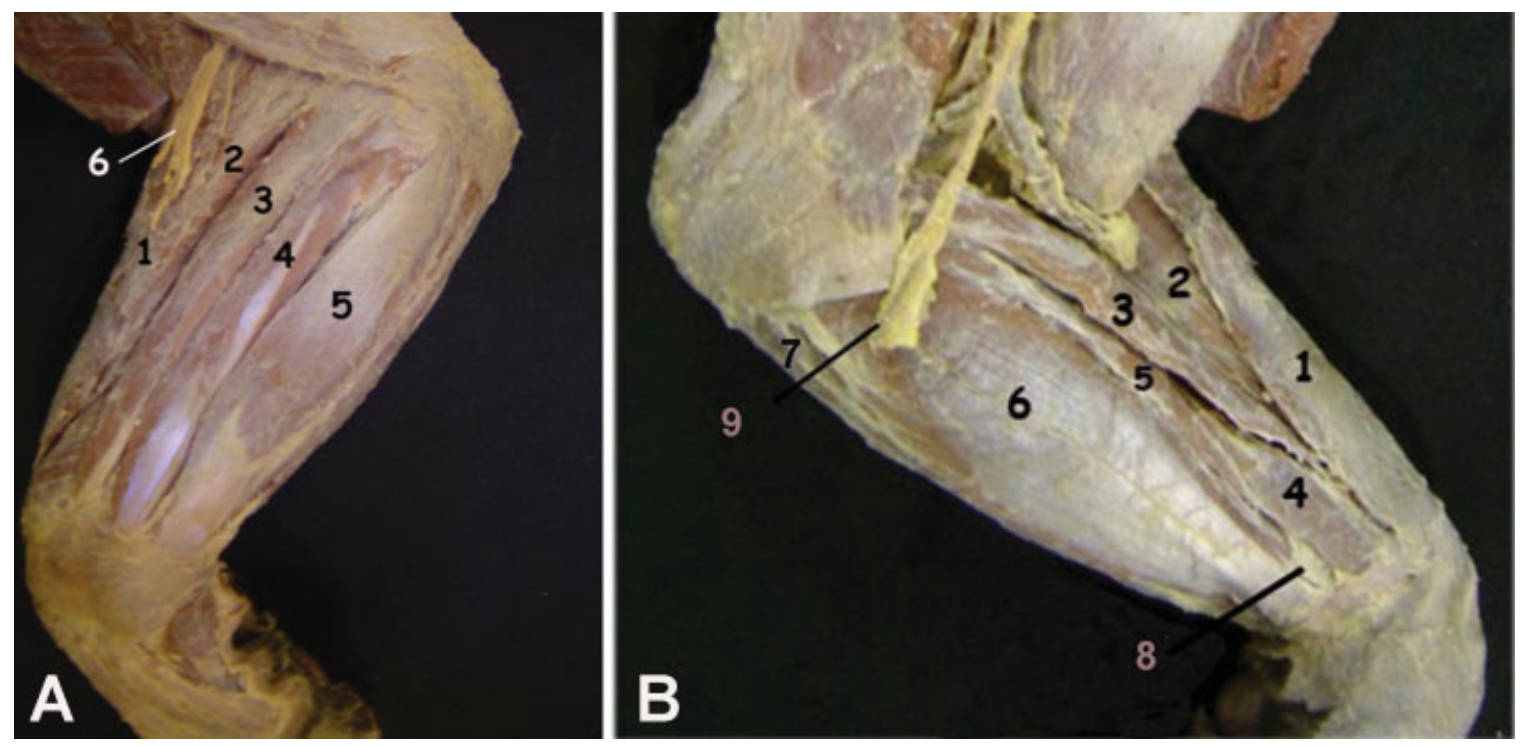

Fig. 1 (A) Lateral view of the forearm and of the hand of the jaguar. 1. Brachioradialis muscle. 2. Extensor carpi radialis muscle. 3. Extensor digitorum communis muscle. 4. Extensor digitorum lateralis. 5. Extensor carpi ulnaris muscle. 6. Radial nerve. (B) Medial view of the forearm and of the hand of the jaguar. 1. Brachioradialis muscle. 2. Extensor carpi radialis muscle. 3. Pronator teres muscle. 4. Flexor carpi radialis muscle. 5. Palmaris longus muscle. 6. Flexor digitorum superficialis muscle. 7. Flexor carpi ulnaris muscle. 8. Median nerve.

humerus, completely separated and located in a median plane. Finally, the radial or deep head originates from the distal middle third of the radius and of the ulna. In the jaguar, this muscular belly had two sesamoid bones. The second head (humeral) formed the tendon of finger I, while the remaining four heads formed the tendons of fingers II to $\mathrm{V}$. Each tendon descended through the proximal annular ligament. The tendons of fingers II to $\mathrm{V}$ continued distally through the distal annular ligament to insert on the palmar side of the distal phalanx ( - Fig. 2B, 3A).

In the jaguar, a great development of the supinator and pronator muscles was observed ( - Table 1 ) ( - Fig. 1A). However, they were less bulky in the ocelot and in the wildcat (-Table 1). The brachioradialis muscle, located under the superficial fascia of the forearm, showed a very developed fleshy belly in the jaguar and in the ocelot, in comparison with that of the wildcat ( $\mathbf{- F i g . ~ 2 A , ~ 3 A ) . ~ T h i s ~ m u s c l e ~ h a d ~ a n ~}$ origin in the proximal third of the caudal surface of the humerus and covered the cranial muscles of the forearm, and then inserted medially at the distal end of the radius and at the proximal row of the carpus by a thick and flattened tendon ( - Fig. 1A).

Beneath the extensor muscles, the supinator muscle was located. In the jaguar, this muscle was formed by a flat muscular belly that spiraled around the proximal end of the radius. At its origin, it presented a short tendon starting from the lateral side of the annular ligament of the radius and from the radial collateral ligament to insert on the cranial surface of the distal third of the radius. In the ocelot and in the wildcat, this muscle was less bulky and ended with a tendon on the cranial surface of the middle third of the radius (-Fig. 4A).

The pronator teres muscle of the jaguar originated through a thick tendon starting from the medial epicondyle of the humerus, to end up being inserted in the cranial face of the distal end of the radius. Then, it extended to the carpal region, where it fused with the flexor retinaculum (-Fig. 1B, 4B) muscle. In the wildcat and in the ocelot, this muscle was less developed ( $\boldsymbol{-}$ Table $\mathbf{1}$ ) and inserted into the medial border of the proximal third of the radius (-Fig. 2A, 3D, 4B).

The pronator quadratus muscle was in a deeper plane. It originated at the flexor surface of the ulna and in the interosseous membrane. Its very fleshy fibers passed obliquely and distally to be inserted in the caudal surface of the radius. In the jaguar and in the ocelot, this muscle was covered by a thick tendon blade.

\section{Discussion}

The myology of the forearm and of the hand of felines was described only for the domestic cat (Felis catus) and for the lion (Panthera leo). ${ }^{12}$ There are some studies performed on the cheetah (Acinonyx jubatus) and on the puma (Puma concolor), but the descriptions are brief and lack morphological details. ${ }^{9,13}$ On the other hand, the description of the muscles of the domestic cat and of the lion are much more extensive, with many well-illustrated and detailed dissections. ${ }^{12,14,15}$

During the evolution of mammals, the supinator and pronator muscles became vestigial or disappeared, as their movement capacity was reduced or lost. Among cats, however, these movements are feasible and very broad, with a pronation of $40^{\circ}$ and a supination of $50^{\circ} .{ }^{16}$ These movements are possible due to the great development of the brachioradialis muscle, which performs the external rotation and the supination of the forearm and of the hand. ${ }^{17-19}$ In felines, the movement of supination is necessary to capture, manipulate and exhaust the prey. ${ }^{20}$ The muscles of the forearm are better developed in wild cats compared with what is described for 

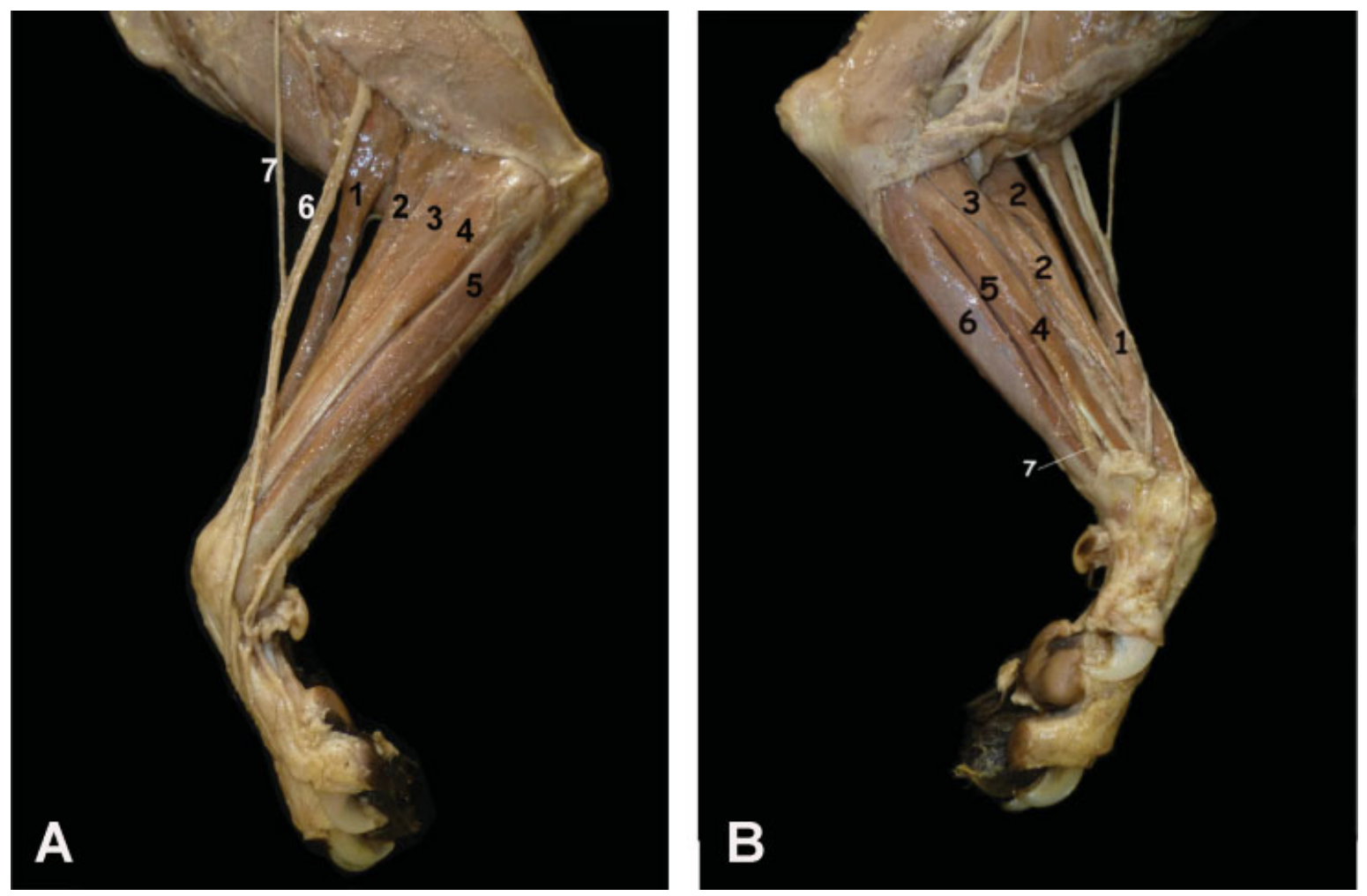

Fig. 2 (A) Lateral view of the forearm and of the hand of the ocelot. 1. Brachioradialis muscle. 2. Extensor carpi radialis muscle. 3. Extensor digitorum communis muscle. 4. Extensor digitorum lateralis muscle. 5. Extensor carpi ulnaris muscle. 6. Surface branch of the radial nerve. 7. Lateral and medial branches of the superficial branch of the radial nerve. 8. Cephalic vein. (B) Medial view of the forearm and of the hand of the ocelot. 1. Brachioradialis muscle. 2. Extensor carpi radialis muscle. 3. Pronator teres muscle. 4. Flexor carpi radialis muscle. 5. Palmaris longus muscle. 6. Flexor digitorum superficialis muscle. 7. Median nerve.

the domestic cat. ${ }^{4,14}$ This seems to be related to the size of the prey and to the adaptation these cats have to hunt in the water or in heights and alone, not in a herd.

The greatest differences were found in the extensor muscles of the carpus and of the fingers, probably because with the distal portion of the thoracic limb rotation, supination and pronation movements are performed with greater amplitude. ${ }^{21}$ However, this observation is unlikely to explain the variation in the number of bellies or tendons of the forearm and hand muscles.

It has been described that the extensor digitorum lateralis muscle of the ocelot has three muscular bellies, while the extensor digitorum communis muscle is formed by four muscular bellies. ${ }^{22}$ This differs from what we have described in our dissections, in which a division of two muscular bellies in both muscles was observed. The same authors described that, in the ocelot, the long palmar muscle terminated in four tendons. ${ }^{22}$ Nevertheless, according to our observations, the termination of the palmaris longus muscle is divided into five tendons in the ocelot and in the jaguar, and into four tendons in the wildcat.

The division of the number of tendons to the fingers is related to the degree of movement of the digits. ${ }^{23}$ These muscular characteristics are consistent with the behavior of each species during the hunting of its prey, ${ }^{24}$ both in the distances they travel and in the size of the different preys.

For authors describe the palmaris longus muscle is not present in the puma, but it is part of the flexor digitorum superficialis. ${ }^{9}$ However, had already described this muscle for the domestic cat separated from the flexor digitorum superficialis, ${ }^{14}$ as we have observed in our dissections in the three feline species studied. However, their tendons in the distal extremity of the middle phalanx ended up attached to the tendons of the flexor digitorum superficialis muscle.

Table 1 Comparative measurements of the brachioradialis, supinator, and pronator muscles

\begin{tabular}{|l|l|l|l|l|l|l|l|l|l|}
\hline Species & \multicolumn{3}{l|}{ Brachioradialis muscle } & \multicolumn{4}{l|}{ Supinator muscle } & \multicolumn{3}{l|}{ Pronator teres muscle } \\
\hline & $\mathrm{L}$ & $\mathrm{W}$ & $\mathrm{T}$ & $\mathrm{L}$ & $\mathrm{W}$ & $\mathrm{T}$ & $\mathrm{L}$ & W & T \\
\hline Jaguar & 21 & 0.5 & 0.4 & 14 & 1.5 & 1.2 & 14.5 & 1.8 & 2.5 \\
\hline Ocelot & 10 & 1 & 0.2 & 8 & 0.8 & 0.5 & 7 & 1.2 & 0.5 \\
\hline Wildcat & 8 & 1 & 0.2 & 5 & 0.5 & 0.2 & 6 & 1 \\
\hline
\end{tabular}

Measurements are expressed in $\mathrm{cm}$.

Abbreviations: L, Lenght; W, Width; T, Thickness. 

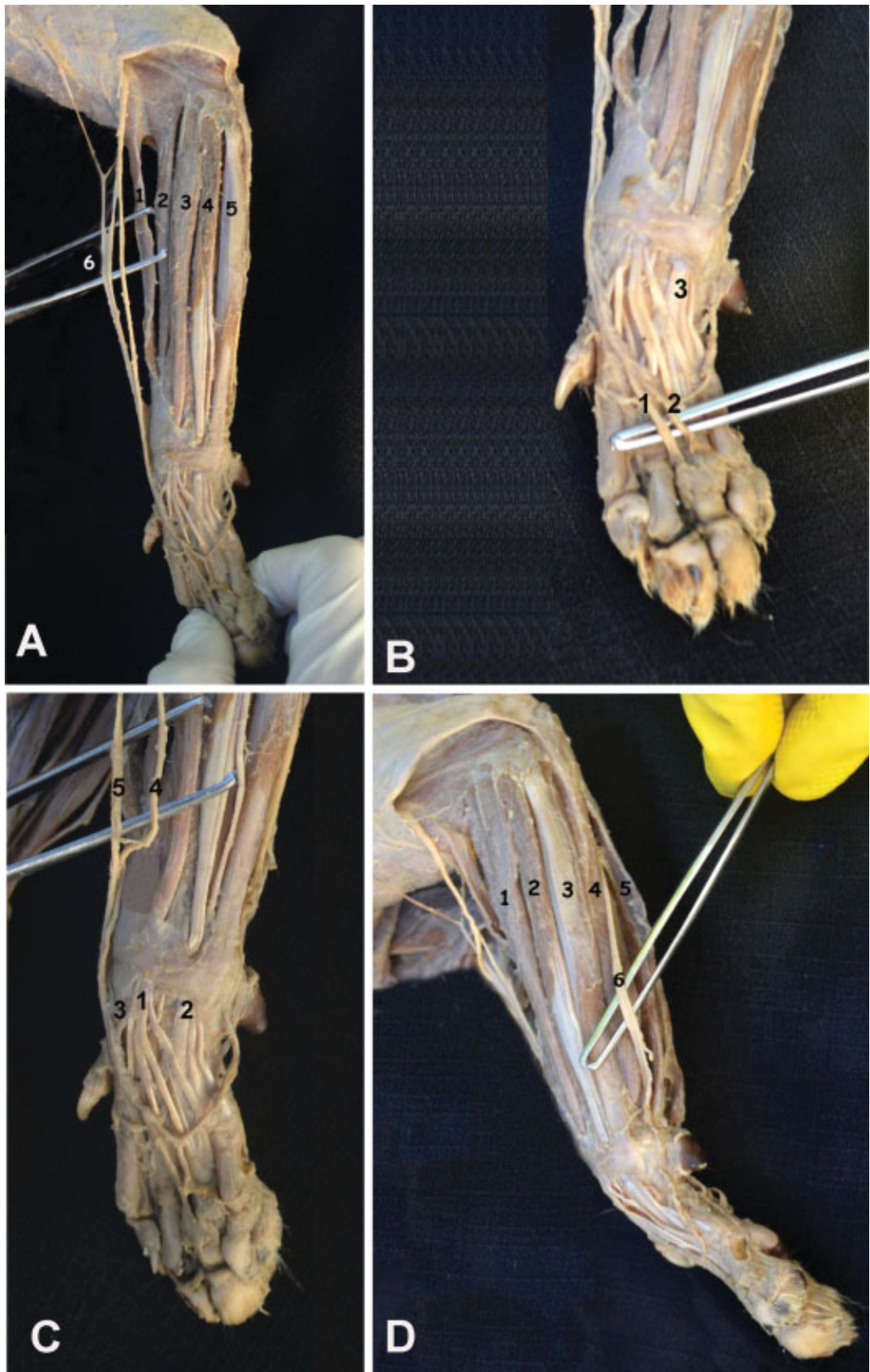

Fig. 3 (A) Side view of the forearm and of the hand of the wildcat. 1. Brachioradialis muscle. 2. Extensor carpi radialis muscle. 3. Extensor digitorum communis muscle. 4. Extensor digitorum lateralis muscle. 5. Extensor carpi ulnaris muscle. 6 . Radial nerve. (B) Palmar view of the hand of the wildcat. 1. Palmar lateral branch 2. Medial palmar branch of the median nerve. 3. Tendons of the flexor digitorum profundus muscle. (C) Lateral view of the forearm and of the hand of the wildcat 1. Extensor carpi radialis muscle. 2. Extensor digitorum communis muscle. 3. Extensor digitorum lateralis muscle. 4. Extensor carpi ulnaris muscle. 5. Flexor carpi ulnaris muscle. 6. Dorsal and palmar branches of the ulnar nerve. (D) Dorsal view of the hand of the wildcat. 1. Tendons of the Extensor digitorum communis muscle 2. Tendons of the extensor digitorum lateralis muscle 3. Tendons of the abductor pollicis 4 . Lateral branches of the radial nerve 5 . Medial branches of the radial nerve. 

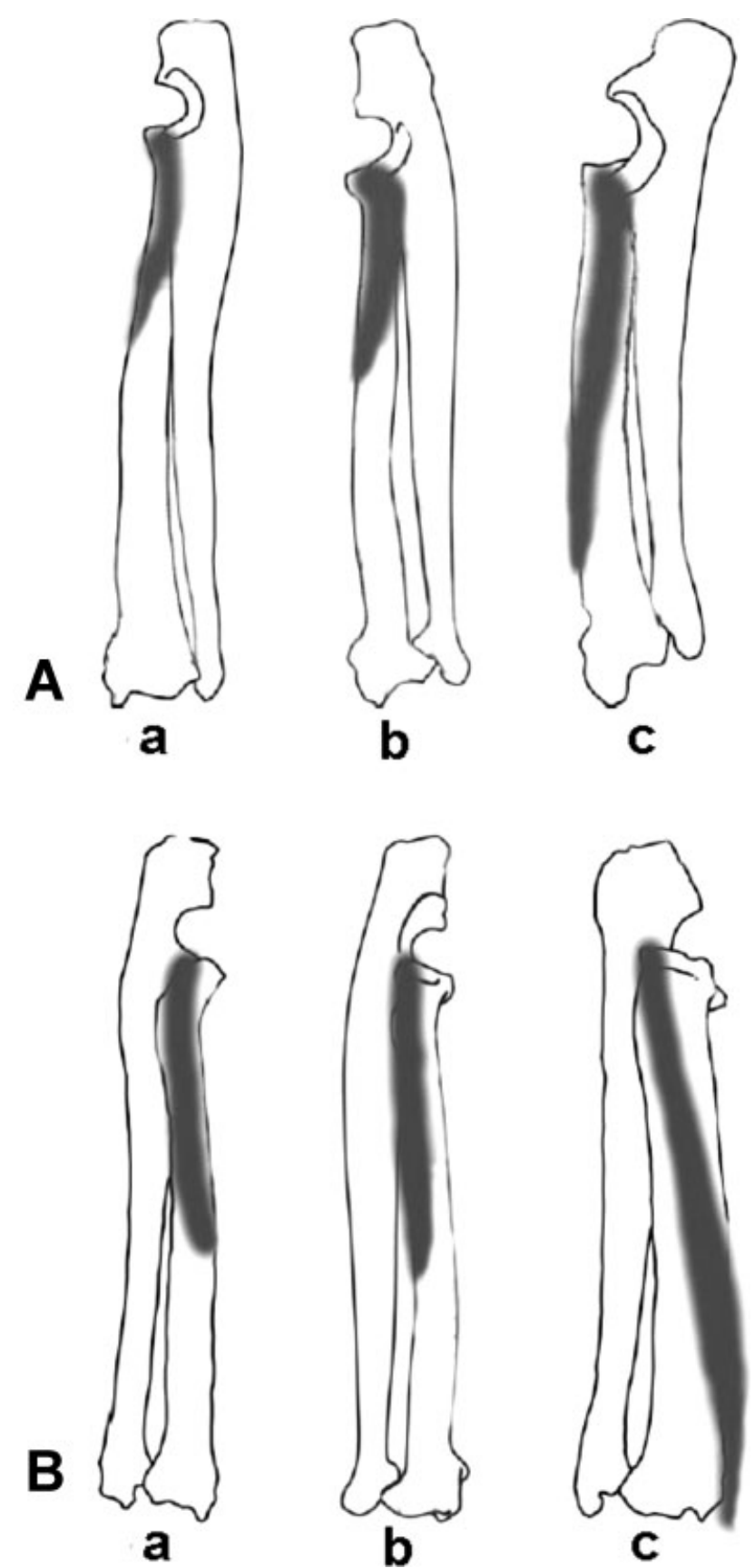

Fig. 4 A. Drawings of the radii and ulnae of the wildcat (a), ocelot (b), and jaguar (c) showing the variation in size and insertions of the supinator muscle. B. Outlines of the radii and ulnae of the wildcat (a), ocelot (b) and jaguar (c) showing the variation in size and insertions of the pronator teres muscle.

\section{Conclusion}

The most distinctive morphological adaptations that we have found between the jaguar, the ocelot, and the wildcat are the powerful supinator and pronator muscles, presenting a variation in the size of their bellies and tendons. These variations among the three species studied are related to ecomorphological variables, such as the size of their prey and their habitat.

The studies of the muscular characteristics of each species of felines and their differences will be particularly useful for future phylogenetic reconstructions. These South American cats have been little studied, and our work represents a contribution on the homologies and differences of the forearm and hand muscles.

Conflicts of interest

The authors have no conflicts of interest to declare.

\section{References}

1 Bart JH, Rebecca JF, Said M, Gutierrez Silverio YM, Doncaster CP. Scrape-marking behavior of jaguars (Panthera onca) and pumas (Puma concolor). J Mammal 2010;91(05):1225-1234

2 Ceballos G, Garcia A, Ehrlich PR. The sixth extinction crisis: Loss of animal populations and species. Journal Cosmology 2010; 8:1821-1831

3 Ledesma MA, Ledesma CO, Schiaffino K, et al. Cytogenetic analysis of Panthera Onca (Felidae: Pantetherinae) from the province of Misiones, Argentina. Mastozoología neotropical 2004;11(01):85-90. Available at: http://www.scielo.org.ar/scielo.php?script=sci_arttext\&pid=S0327-93832004000100009\&lng=es

4 Sánchez HL, Silva LB, Rafasquino ME, et al. Anatomical study of the forearm and hand nerves of the domestic cat ( Felis catus), puma ( Puma concolor) and jaguar ( Panthera onca). Anat Histol Embryol 2013;42(02):99-104

5 Silva LB, Sánchez HL. La inervación del miembro torácico en felinos. Analecta Vet 2013;33(01):10-17

6 Diogo R, Pastor F, De Paz F, et al. The head and neck muscles of the serval and tiger: homologies, evolution, and proposal of a mammalian and a veterinary muscle ontology. Anat Rec (Hoboken) 2012;295(12):2157-2178

7 Schaller O. Nomenclatura Anatómica Veterinaria Ilustrada. Acribia1996 Zaragoza

8 Nomina Anatomica Veterinaria. (NAV). International Committee on Veterinary Gross Anatomical Nomenclature. 5 th ed. Hannover, Columbia, Gent, Sapporo: Editorial Committee; 2012:18-23

9 Concha I, Adaro L, Borroni C, Altamirano C. Consideraciones Anatómicas sobre la Musculatura Intrínseca del Miembro Torácico del Puma (Puma concolor). Int J Morphol 2004;22(02):121-125

10 Geertsema A. Impressions and observations on serval behaviour in Tanzania, East Africa. Mammalia 1976;40:13-19

11 SeymourKL. Panthera onca. Mamm Species 1989;340:1-9

12 Barone R. La myologie du lion (Panthera leo). Mammalia 1967;31 (03):459-514

13 Ross FO. Myology of the cheetah, or hunting leopard of India (Felis jubata). Proc R Ir Acad 1876;2(03):23-32

14 Reighard J, Jennings HS. Anatomy of the cat. New York: Rinehart \& Winston; 1966:582-592

15 Medina Puentes R, Morales Munoz P Concha Albornoz and Borroni Gonzalez. Descripción Anatómica de la Inervación del Miembro Pélvico de León Africano (Panthera leo). Int J Morphol 2014;32(03):889-894

16 Dyce KM. Thoracic member. In: Dyce KM, Sack WO, Wensing CJG eds. Veterinary Anatomy Treaty. 4th ed. México: El Manual Moderno S. A. de C. V; 2010:476-489

17 Níkel R, Schummer A, Seiferle E, Frewein J, Wilkens H, Wille K. The Locomotor System of Domestic Mammals. Berlin: Verlag Paul Parey; 1986:515

18 Liebich HG, Maierl J, König. HE. Thoracic member. In: König. HE, Liebich HG eds. Veterinary Anatomy of Domestic Mammals: Textbook and Colour Atlas. Porto Alegre: Artmed; 2016: 165-234

19 De Souza PJ, Dos Santos LMPR, Nogueira DMP, Abidu-Figueiredo M, Santos ALQ. Occurrence and morphometrics of the brachioradialis muscle in wild carnivorans (Carnivora: Caniformia, Feliformia). Zoologia 2015;32(01):23-32

20 Hudson PE, Corr SA, Payne-Davis RC, Clancy SN, Lane E, Wilson AM. Functional anatomy of the cheetah (Acinonyx jubatus) forelimb. J Anat 2011;218(04):375-385 
21 Crouch J. Text-Atlas of Cat Anatomy. Philadelphia: Lea and Febiger; 1969:101-108

22 Julik E, Zack S, Adrian B, et al. Functional Anatomy of the Forelimb Muscles of the Ocelot (Leopardus pardalis). J Mamm Evol 2012;19 (04):277-304

23 Ruberte J, Sautet J, Navarro, M, et al. Thorax and thoracic limb. In: DoneS H, Goody PC, Evans SA, Strickland NC eds. Color Atlas of
Veterinary Anatomy: the dog and the cat. España: Elsevier Mosby; 2010:171-193

24 El-Ghazali HM, El-behery El. Comparative Macro-Anatomical Observations of the Appendicular Skeleton of New Zealand Rabbit (Oryctolagus cuniculus) and Domestic Cat (Felis domestica) Thoracic Limb. Inter J Vet Sci 2018; $7: 127-133$ 